\title{
PENSAR A EDUCAÇÃO INCLUSIVA EM MUSEUS A PARTIR DAS EXPERIÊNCIAS DA PINACOTECA DE SÃO PAULO *
}

\author{
Milene Chiovatto ** \\ Pinacoteca do Estado de São Paulo \\ Gabriela Aidar ${ }^{* * *}$ \\ Pinacoteca do Estado de São Paulo
}

\section{RESUMO:}

O texto discute as transformações em nossa compreensão do papel do museu ao assumir uma função cada vez mais social e inclusiva. Apresenta um breve histórico da implantação do Núcleo de Ação Educativa da Pinacoteca do Estado de São Paulo, focando especificamente nas ações educativas inclusivas realizadas junto aos chamados "não-públicos de museus", bem como nas ações educacionais extramuros desenvolvidas.

\section{PALAVRAS-CHAVES:}

educação, museu, inclusão sociocultural, vulnerabilidade social, ação extramuros.
Inclusive Education in Museums. Case study: Pinacoteca do Estado de São Paulo

ABSTRACT:

The text discusses transformations in our understanding of the museum's role in assuming an increasingly more social and inclusive function. It presents a brief history of the implantation of the Education Department at the Pinacoteca do Estado de São Paulo, focusing on the inclusive educational actions undertaken with non-audiences, as well as outreach initiatives.

\section{KEY-WORDS:}

education, museum, sociocultural inclusion, social vulnerability, outreach.

\footnotetext{
** Coordenadora do Núcleo de Ação Educativa da Pinacoteca do Estado de São Paulo; mchiovatto@ pinacoteca.org.br

*** Coordenadora dos Programas Educativos Inclusivos da Pinacoteca do Estado de São Paulo; gaidar@ pinacoteca.org.br
} 
Pensar a educação inclusiva em museus é admitir que esta instituição tem, na sociedade contemporânea, uma função bastante distinta daquela para a qual foi criada nos séculos XVIII e XIX; deixando de ser acúmulo passivo de objetos para assumir um papel ativo na interpretação da cultura, na construção do conhecimento, no fortalecimento da cidadania, no respeito à diversidade cultural e no incremento da qualidade de vida; ou seja, assumir plenamente seu papel social.

\section{Alguns conceitos referenciais para a educação inclusiva em museus}

Como princípio para a elaboração das ações educativas que propomos e realizamos, partimos da ideia da cultura como um direito fundamental. Os chamados direitos culturais fazem parte dos direitos humanos fundamentais, somando-se aos direitos políticos, sociais e econômicos. Isto se encontra presente em diversos documentos, entre os quais a Declaração Universal dos Direitos Humanos, proclamada pela Assembleia Geral das Nações Unidas em 1948, que em seu Artigo XXVII afirma:"toda pessoa tem o direito de participar livremente da vida cultural da comunidade, de fruir as artes e de participar do processo científico e de seus benefícios."

Entretanto, os direitos culturais, diferentemente dos direitos sociais, ainda são pouco conhecidos e praticados. Segundo o Ministério da Cultura do Brasil, são eles:

- direito à identidade e à diversidade cultural (ou direito ao patrimônio cultural).

- direito à participação na vida cultural, que compreende: direito à livre criação; direito ao livre acesso; direito à livre difusão; direito à livre participação nas decisões de política cultural.

- direito autoral.

- direito ao intercâmbio cultural (nacional e internacional). (Ministério da Cultura, 201 I: 19).

Alguns autores buscam relacionar os direitos culturais especificamente à prática dos museus, como o britânico David Anderson (2012: 224), que propõe:

Baseados nas leis internacionais, quais direitos os cidadãos das democracias ocidentais possuem em relação aos museus? Proponho que todos têm direitos ao: I) reconhecimento de suas identidades culturais; 2) contato com outras culturas; 3 ) participação em atividades culturais; 4) oportunidades para a criatividade; e 5) liberdade de expressão e de julgamento crítico.

Mas como os museus podem efetivar isso em sua prática? O mesmo autor prossegue afirmando isto ser possível por meio de diversas estratégias, como:

I) Compromisso para reduzir as desigualdades no engajamento com a cultura; 2) aceitação de que a população como um todo é tão capaz, inteligente e culturalmente experiente quanto os profissionais de museus; 3) ação efetiva para promover maiores oportunidades de aprendizado e criatividade; 4) participação de públicos alvo e personalização de serviços do museu para suas necessidades; 5 ) extensão de seus serviços para além da instituição até as comunidades; 6 ) investimento contínuo em pesquisas de aprendizado e avaliação para apoiar essas ações; e 7) redirecionamento de pensamento daquilo que querem oferecer para o que é necessário para o bem estar individual e comunitário. (Anderson, 2012: 224). 
Outro conceito que costuma articular muitas das propostas voltadas a grupos de "não públicos" de museus, compostos por pessoas que não são frequentadores habituais de instituições oficiais de cultura, é o de comunidade. Assim como outros conceitos a serem discutidos aqui, tais como inclusão sociocultural e mesmo acessibilidade em museus, a caracterização da ideia abstrata de comunidade é escorregadia e depende de tradições intelectuais e sociais específicas. Daniel Castro, diretor do Museo Quinta de Bolívar e da Casa del Florero, em Bogotá, na Colômbia, em sua apresentação e texto escrito para o seminário Colaborações - trocas entre comunidades, museus e práticas educativas Colômbia/Brasil, realizado em outubro de 2013 na Pinacoteca ', discute a variedade de possibilidades que o termo comunidade implica, destacando ser fundamental especificar e conceituar este termo, enfatizando que

esta reflexão prévia é necessária para trabalhar com estes mesmos grupos sociais, ou se tende a evitar esse ponto, adotando um voluntarismo, certamente bem intencionado, mas, possivelmente, um pouco irrefletido. (...) existem muitas instituições públicas e privadas de nível mundial que podem desenvolver ações deslocadas e "pouco conscientes" em função desse eufemismo (...), querendo fazer-nos acreditar que pela inclusão do termo em suas ações estão operando de maneira efetiva. (Castro, 2013: 04).

Anne Kershaw, professora da Universidade de Deakin, na Austrália, parte de uma premissa bastante abrangente para tentar definir o que podem ser as comunidades desde a perspectiva museal. De acordo com a autora, o termo "comunidade" refere-se a qualquer grupo de pessoas que optam por identificar-se entre si.As comunidades podem ser definidas de acordo com: a geografia, a cultura; circunstâncias comuns ou semelhantes (por exemplo, comunidades de refugiados), condições econômicas e sociais (comunidades socialmente excluídas); ou hobbies e interesses.

É importante para os museus perceberem a complexidade da noção de comunidade. Qualquer indivíduo terá vários, e possivelmente até mesmo conflitantes, vínculos comunitários. A participação na comunidade é muitas vezes voluntária, no entanto, ela também pode ser atribuída - por exemplo, ser parte de uma comunidade de pessoas socialmente excluídas. Comunidades diferem em termos de recursos, capacidades, cultura e comportamento. Esta diversidade existe entre - e dentro - das comunidades. (Kershaw, 20I3: I2).

Neste ponto, faz-se relevante esclarecer o uso que fazemos do conceito de inclusão social. Em nossa prática, ao utilizarmos o conceito de exclusão social, nos referimos aos processos pelos quais um indivíduo ou grupo tem acesso limitado às açõese instituições tidas como referenciais e consideradas padrão da vida social, e por isso encontram-se privados da possibilidade de uma participação plena na sociedade em que vivem. Esses indivíduos ou grupos quando se encontram socialmente vulnerabilizados podem enfrentar diversas e simultâneas situações de exclusão: a perda de direitos pela exclusão de sistemas políticos, a perda de recursos pela exclusão dos mercados de trabalho e a deterioração das relações pessoais pelo enfraquecimento de laços familiares e comunitários, ficando, assim, sujeitos a um contexto de privação múltipla (De Haan \& Maxwell, 
1998: 03). A essa situação podemos acrescentar, ainda, o enfraquecimento de sentimentos de pertencimento e reconhecimento cultural pela exclusão dos circuitos e instituições da cultura oficialmente instituída.

Se nos baseamos na definição de exclusão social como um processo e um estado pelos quais dinâmicas sociais e instituições limitam alguns grupos de uma ampla participação na sociedade, podemos argumentar que as instituições culturais podem executar um papel numa rede de elementos excludentes, ou por oposição, serem ferramentas para a inclusão social. Além disso, dada a natureza multidimensional da exclusão, políticas voltadas para a inclusão devem assumir uma abordagem interdisciplinar, o que pode incluir serviços sociais assim como serviços culturais, posicionando as instituições culturais na arena dos problemas sociais, mais uma vez indicando que como profissionais da cultura não devemos nos separar das demandas sociais.

Conforme afirma Mark O’Neill ((2002: 34), atual Diretor de Políticas e Pesquisas de Glasgow, na Escócia,

As implicações para o fato dos processos de inclusão e exclusão serem auto-reforçados/gerados são muito claras: qualquer organização que não esteja trabalhando para romper as barreiras está ativamente mantendo-as. A neutralidade não é possível.

O conceito de inclusão social significa buscar ativamente remover as barreiras, reconhecendo que pessoas que foram apartadas por gerações precisam de apoio adicional numa ampla variedade de formas, de modo a permitir que possam exercer seu direito de participação em muitas das oportunidades que os privilegiados e escolarizados têm garantidas. (O'Neill, 2002: 34, 37).

Quando tratamos da acessibilidade em museus, diferentes concepções do termo se impõem. Em nossa prática no Núcleo de Ação Educativa da Pinacoteca utilizamos o termo acessibilidade no que consideramos uma acepção mais ampla, envolvendo não apenas as questões ligadas à promoção de acesso físico, por meio da garantia de circulação e afluxo de público às instituições (com a utilização de rampas, elevadores e mesmo com a gratuidade nos ingressos), mas também - e especialmente - no que se refere a aspectos intangíveis do contato com os museus, como aqueles relacionados ao acesso cognitivo, ou seja, ao desenvolvimento da compreensão dos discursos expositivos e patrimoniais, e ao que podemos chamar de acesso afetivo ou atitudinal, por meio do desenvolvimento da identificação com sistemas de produção e fruição da arte e da cultura, e da confiança e prazer pela inserção no espaço do museu. Com a ampliação da compreensão e uso do termo, os museus podem desenvolver ações de acessibilidade que incluam diversos grupos excluídos dos processos e sistemas oficiais de cultura (Chiovatto, Aidar, Soares, e Amaro, 2010: 18).

\section{A Pinacoteca de São Paulo e seu Núcleo de Ação Educativa}

A Pinacoteca está localizada no Parque da Luz, um parque público no chamado centro antigo da cidade da São Paulo, uma área com boa infraestrutura de serviços e equipamentos públicos e privados e com importantes áreas comerciais, mas que conta ainda assim com populações vivendo em condições precárias de subsistência, similares às de áreas periféricas empobrecidas da cidade de São Paulo. O museu faz parte de um polo cultural local que compreende cinco museus e uma sala de concertos. É o mais antigo museu de arte do estado de 
São Paulo, fundado em 1905. É uma instituição pública, pertencente ao Governo do Estado de São Paulo, de gestão privada, por meio de contratos de gestão com a APAC - Associação Pinacoteca Arte e Cultura, uma organização social de cultura. Atualmente possui cerca de 9.000 obras, entre pinturas, desenhos, gravuras, esculturas, fotografias e objetos de arte brasileira e internacional dos séculos $\mathrm{XVIII}$ aos dias de hoje. O museu conta com uma exposição de longa duração do acervo, e uma extensa e variada programação de exposições temporárias. A partir de 2004, conta ainda com mais um edifício, a Estação Pinacoteca, que apresenta exposições temporárias de arte, além de abrigar o Memorial da Resistência, espaço dedicado a resguardar a história da resistência e repressão políticas dos momentos ditatoriais do país do século XX.

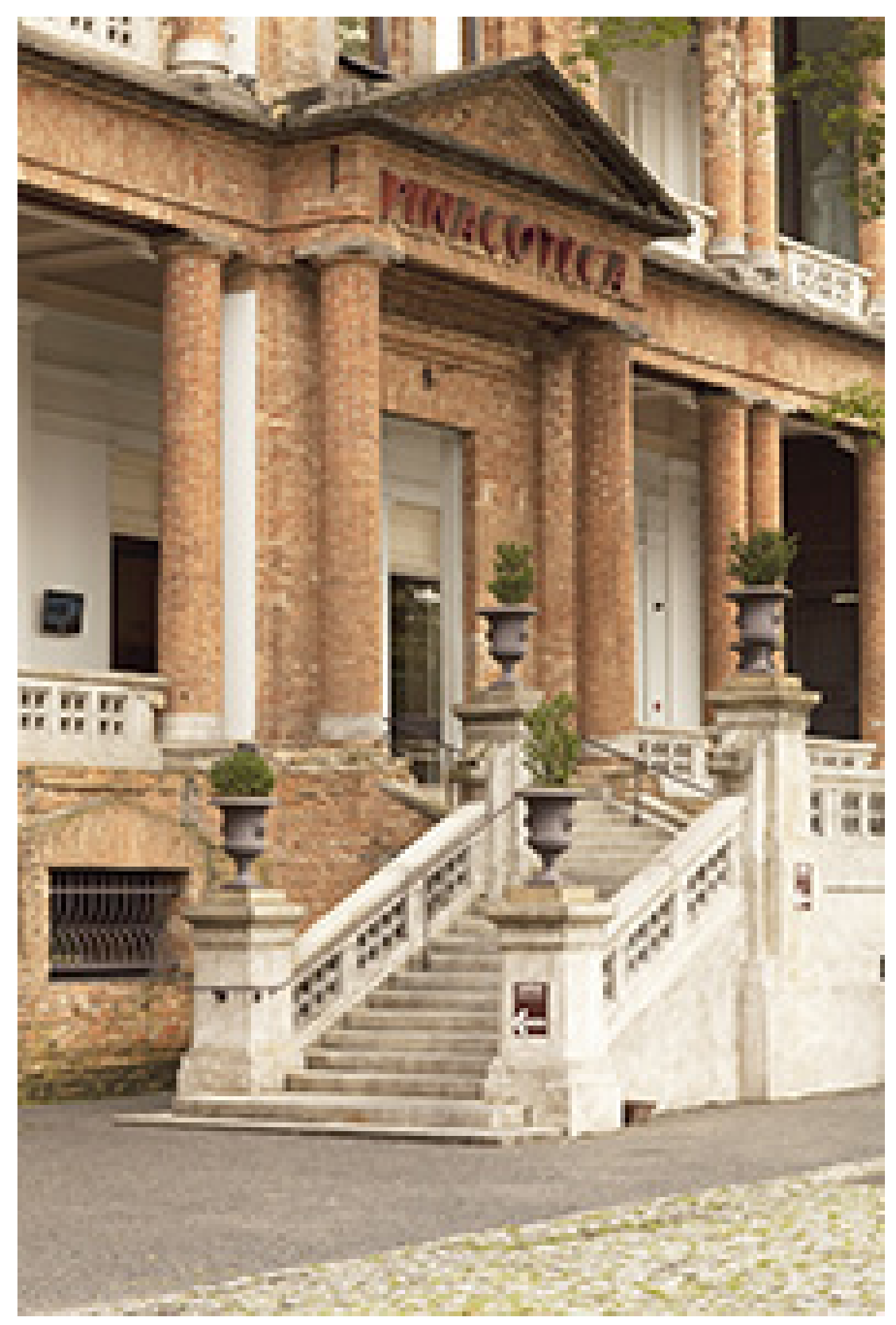

Entrada da Pinacoteca 
Seu Núcleo de Ação Educativa, estruturado desde 2002, tem como objetivos gerais desenvolver ações educativas a partir das obras do acervo do museu; promover a qualidade da experiência do público no contato com as obras de arte; garantir a ampla acessibilidade ao museu, além de incluir e transformar em frequentes, públicos não habitualmente frequentadores. Atualmente, os programas desenvolvidos pelo Núcleo de Ação Educativa são:

1. Programa de Atendimento ao Público Escolar e em Geral - responsável por realizar atividades junto a estes públicos, por meio de visitas educativas, atividades de produção plástica e poética, por processos formativos para professores, ou ainda no atendimento do público em geral, com propostas específicas para famílias, por exemplo.

2. Programas para professores - encontros preparatórios para professores, que visam dar subsídios pedagógicos acerca de temas e conteúdos relacionados ao acervo da Pinacoteca e de algumas de suas exposições temporárias; além de processos formativos sobre patrimônio, cultura e identidade em outras cidades do estado de São Paulo.

3. Dispositivos para Autonomia da Visita - recursos de mediação e propostas educativas nas exposições de longa duração do acervo e em algumas exposições temporárias do museu destinadas ao público em geral que visam a independência em relação à presença física do educador, incluindo a Educateca, jogos educativos deixados à disposição do público visitante.

\section{Programas Educativos Inclusivos:}

Programa Educativo para Públicos Especiais;

Programa Consciência Funcional;

Programa Meu Museu;

Programa de Inclusão Sociocultural.

De acordo com o foco deste texto, trataremos especificamente dos Programas Educativos Inclusivos desenvolvidos ao longo dos últimos dez anos pelo Núcleo de Ação Educativa da Pinacoteca. Tais programas estruturam-se a partir das demandas e lógicas de seus públicos alvo, caracterizados por grupos de chamados "não públicos" de museus, compostos por pessoas que não são frequentadores habituais de instituições oficiais de cultura, tais como museus, centros culturais etc. Atualmente participam desses programas grupos em situação de vulnerabilidade social majoritariamente por questões socioeconômicas, grupos de pessoas com deficiências e transtornos mentais, grupos de idosos e também funcionários da própria Pinacoteca, em particular ligados às funções de recepção de visitantes, manutenção e equipes de segurança e limpeza.

Cada um dos quatro programas que compõem os chamados Programas Educativos Inclusivos desenvolve uma série de ações e projetos elaborados e constantemente avaliados a partir das necessidades apresentadas pelos grupos participantes. Neste ponto, nos valemos das ideias de diversos teóricos da educação que apontaram a importância de se trabalhar com o conhecimento prévio dos educandos para a realização de ações educativas efetivas. Entre eles, destaca-se o educador Paulo Freire, que apontou para a necessidade de se trabalhar com temas significativos da experiência cotidiana dos educandos, ao que chamou de "temas geradores", conforme afirma: "Será a partir da situação 
presente, existencial, concreta, refletindo o conjunto de aspirações do povo, que poderemos organizar o conteúdo programático da educação ou da ação política”. Freire (2005: 100).

O Programa Educativo para Públicos Especiais tem por objetivo garantir a fruição da arte para pessoas com deficiências sensoriais, físicas e intelectuais por meio da acessibilidade física e sensorial aos espaços expositivos e obras do acervo da Pinacoteca. Isso se dá por meio da realização de atendimentos a grupos de pessoas com e sem deficiências, e da formação de profissionais das áreas de artes, saúde, museus e educação para ações inclusivas em suas organizações de origem. Entre as ações desenvolvidas pelo Programa, destacam-se visitas educativas com a utilização de recursos de apoio multissensoriais, a fim de ampliar o contato com a arte por meio de outros sentidos além da visão; atendimentos especializados por educadora surda em Libras (Língua Brasileira dos Sinais) para o público surdo; publicações em dupla leitura (tinta com letras ampliadas e Braille), acompanhadas de audioCD; além de ações que visam favorecer a visitação autônoma de públicos com deficiência sensorial ao acervo da Pinacoteca, como o videoguia, disponibilizado para o público surdo em visita à exposição do acervo, e a Galeria Tátil de Esculturas Brasileiras, concebida para a autonomia de pessoas com deficiência visual, mediada pela utilização de audioguia.

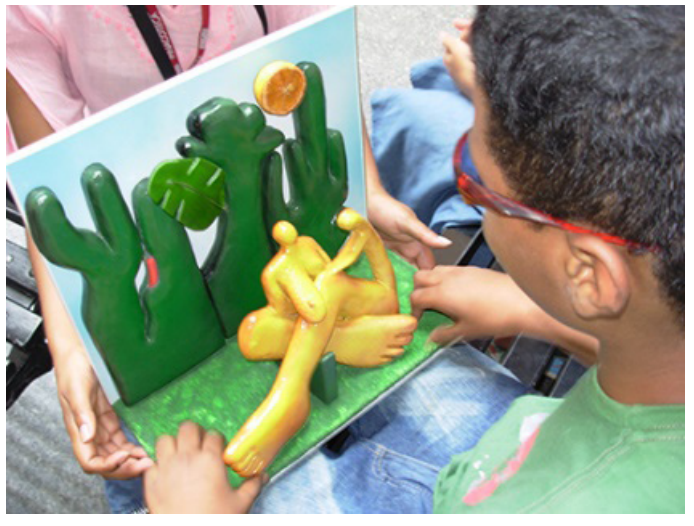

Visita a grupo com deficiência com utilização de recurso de apoio multissensorial

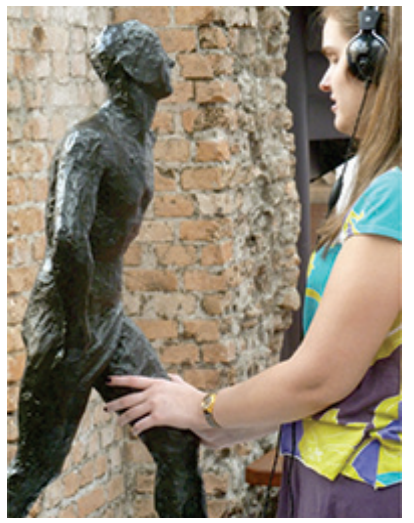

Visitante com deficiência visual utilizando o audioguia na Galeria Tátil de Esculturas Brasileiras

O Programa Consciência Funcional desenvolve atividades educativas continuadas com os funcionários da Pinacoteca. Em parceria com a área de Recursos Humanos do museu, desenvolve atividades junto a profissionais do atendimento ao público (atendentes e recepcionistas), com a equipe de manutenção e com todos os funcionários que iniciam suas atividades na Pinacoteca (estagiários, educadores, voluntários, entre outros), além de prestadores de serviço das equipes de segurança e limpeza. Seu objetivo é estabelecer um diálogo constante com os funcionários dos diferentes núcleos da Pinacoteca, ampliando sua percepção da variedade de ações desenvolvidas pela instituição e de sua função social. O Programa pretende ainda auxiliar no processo de desenvolvimento pessoal e profissional dos funcionários do museu, tratando-os de maneira sensível e atuando a fim de promover sua inserção cultural. Para isso, desenvolve atividades para receber e acolher os novos funcionários à instituição; produz materiais informativos internos sobre as exposições temporárias da Pinacoteca; organiza visitas educativas a essas exposições; promove formações 
em serviço com aspectos técnicos e aspectos psicossociais; promove uma visita externa destes funcionários a outra instituição de cultura; organiza oficinas de experimentação plástica, além de realizar uma atividade especial anual em comemoração ao Dia das Crianças, para filhos e parentes de funcionários.

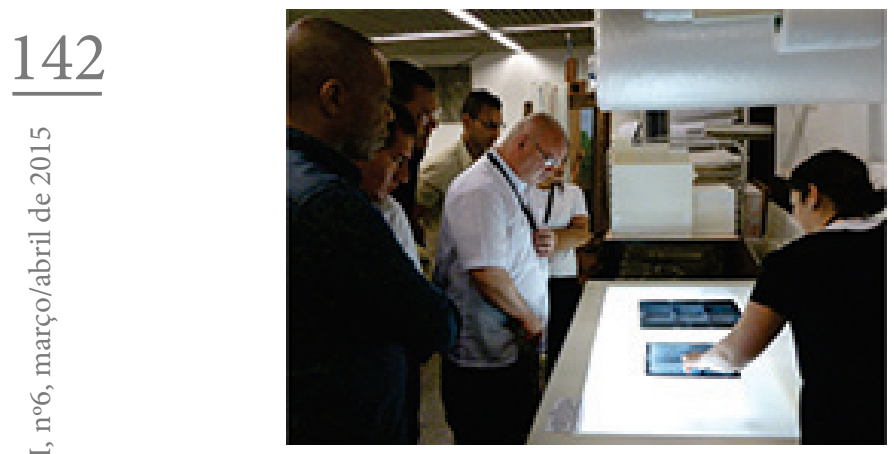

Visita de grupo de recepcionistas ao Laboratório de Restauro da Pinacoteca

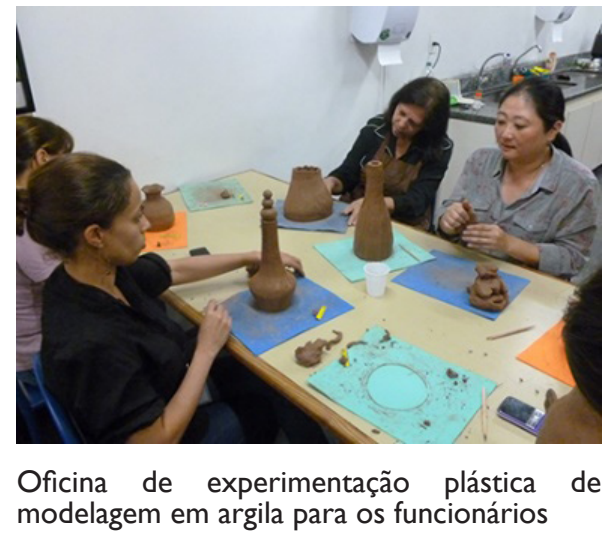

O Programa Meu Museu, iniciado em abril de 20I3, promove ações educativas voltadas a grupos de idosos, a fim de estimular sua visitação à Pinacoteca, fortalecer sua autonomia e estabelecer relações entre suas memórias pessoais e as memórias sociais preservadas pelo museu. Isto se dá por meio de realização de visitas educativas a grupos de idosos, de um curso de formação para educadores e profissionais que atuam junto a esses grupos e da elaboração de um material impresso educativo para os participantes das ações.

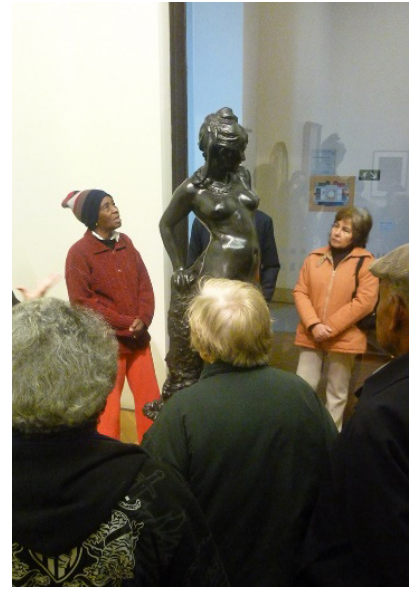

Visita educativa a grupo de idoso

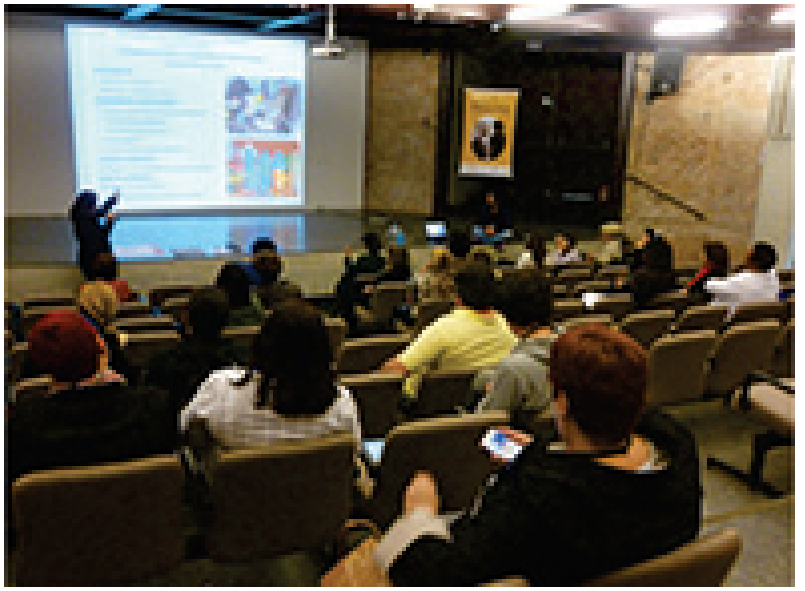

Aula no curso Idosos e o museu: possibilidades educativas

Por fim, o Programa de Inclusão Sociocultural visa promover o acesso qualificado aos bens culturais presentes na Pinacoteca a grupos em situação de vulnerabilidade social ${ }^{2}$, com pouco ou nenhum contato com instituições oficiais da cultura. O Programa busca contribuir para a promoção de mudanças qualitativas no cotidiano desses grupos e ainda para a formação de novos públicos de museus.

2 A Política Nacional de Assistência Social, do Governo Federal, utiliza os termos "cidadãos e grupos que se encontram em situação de vulnerabilidade e riscos..." para definir seus usuários. O uso desse conceito implica uma maior abrangência de situações, nas quais a exclusão pela pobreza é mais uma delas e não a única, assim como a falta de acesso às políticas e aos serviços públicos. $O$ documento também relaciona as situações de vulnerabilidades e riscos com a violação de direitos. Política Nacional de Assistência Social (2004). 
Os grupos com os quais trabalhamos podem variar ao longo dos anos, mas em geral compõem-se de grupos em situação de rua, como usuários de albergues e centros de convivência; moradores de habitações precárias, como cortiços e ocupações, abundantes no centro da cidade; cooperativas e grupos de artesãos voltados à geração autônoma de renda; dependentes químicos em tratamento de saúde; jovens e crianças de setores populares participantes de projetos socioeducativos principalmente ligados a ONGs; educadores sociais, entre outros, sempre ligados a iniciativas da educação não-formal.

O Programa de Inclusão Sociocultural teve início em 2002, a partir da percepção da descontinuidade entre o que acontecia dentro e fora da Pinacoteca. Nesse ano realizamos uma pesquisa de perfil de público espontâneo cujos resultados comprovaram uma situação que podia ser percebida no convívio diário com o museu e seus visitantes: que estes possuem um perfil bastante específico e privilegiado, com altíssima escolaridade e renda familiar entre média e alta, além de não serem moradores do entorno ou mesmo de regiões próximas ao museu, distinguindo-se, assim, do público que frequenta seus arredores (Pinacoteca do Estado de São Paulo, 2002).

Como forma de estabelecer relações construtivas com os grupos vulnerabilizados do entorno do museu, iniciamos as ações do Programa com a realização de um mapeamento das organizações sociais da região que poderiam vir a ser parceiras para os trabalhos, e com a participação em algumas iniciativas comunitárias que congregam agentes e entidades locais, por meio das quais pudemos conhecer melhor as questões e demandas da região e os potenciais parceiros. Assim, as ações educativas do Programa tiveram início com grupos do entorno da Pinacoteca, e atualmente trabalhamos com diversos grupos da região central da cidade, ainda que não exclusivamente.

As ações desenvolvidas pelo Programa estruturam-se a partir de parcerias com organizações sociais para a realização de visitas educativas continuadas aos grupos; também é desenvolvido um curso anual de formação para educadores sociais; ações educativas extramuros junto a grupos de adultos em situação de rua do entorno do museu; além da realização de processos de educação patrimonial junto a grupos comunitários, processos avaliativos e pesquisas de público. Também produzimos no âmbito deste programa algumas publicações, como o Arte+, um material impresso para educadores sociais com foco na educação em arte e na educação patrimonial, a fim de apoiá-los em suas práticas socioeducativas.

Além dos atendimentos diferenciados que, neste Programa prezam pela continuidade, realizando sempre interações feitas a partir da demanda dos parceiros e das potencialidades do museu, realizamos há 6 anos uma ação educativa extramuros responsável por atuar em parceria com duas organizações para adultos em situação de rua do entorno do museu.

Neste projeto, optamos por trabalhar com esse perfil de público em função de que sua situação de vulnerabilidade encontra ainda um forte estigma social e inclusive uma pretensa "culpabilidade" por sua própria situação, além da baixa oferta de projetos socioeducativos em arte e cultura para tais grupos.

Assim, em seus locais de acolhida, chamadas casas de convivência, são desenvolvidas semanalmente atividades de oficinas de gravura e de criação de textos de caráter poético. Estas escolhas foram pautadas pelo repertório cultural da maior parte desta população, vinda de estados do nordeste do Brasil, 


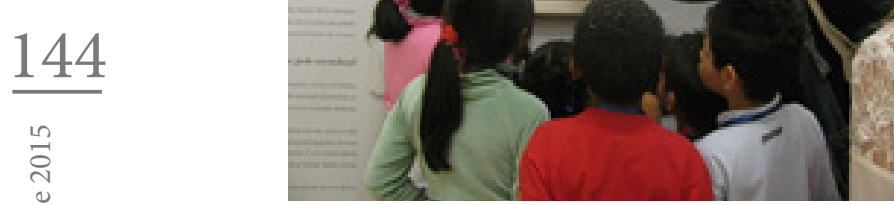

Visita educativa a crianças frequentadoras de ONG vizinha ao museu

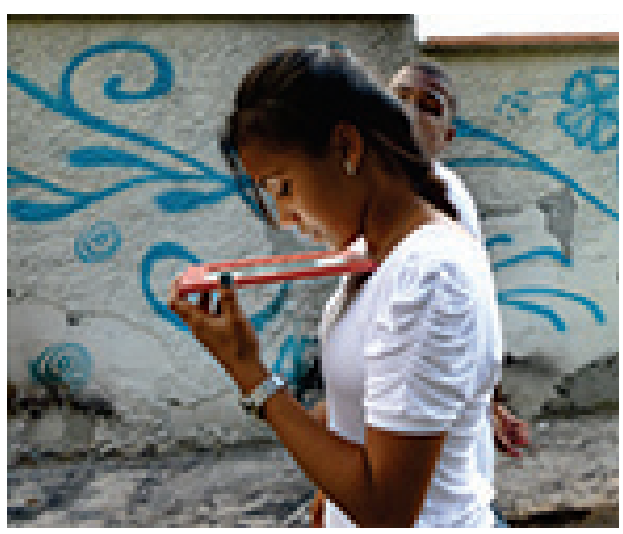

Jovens do CJ União realizando atividade de exploração de seu bairro

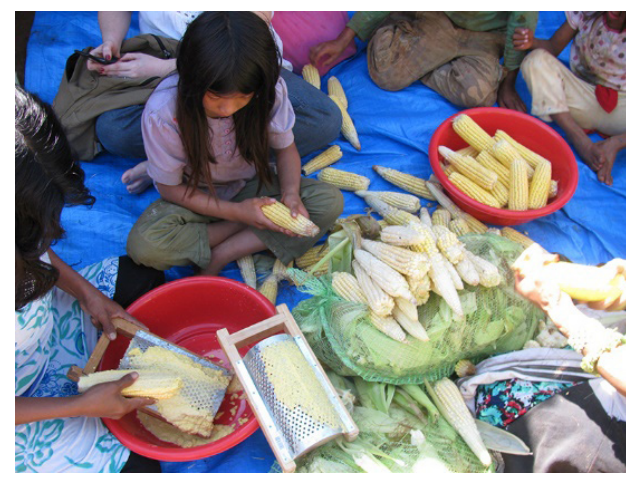

Atividade de preparação de receita da culinária Guarani

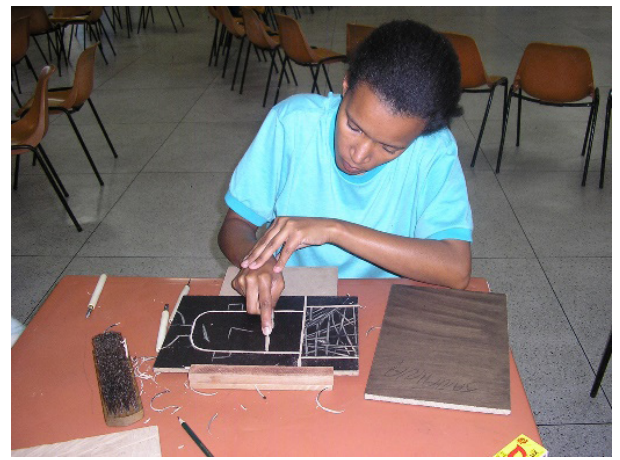

Oficina de xilogravura da ação educativa extramuros

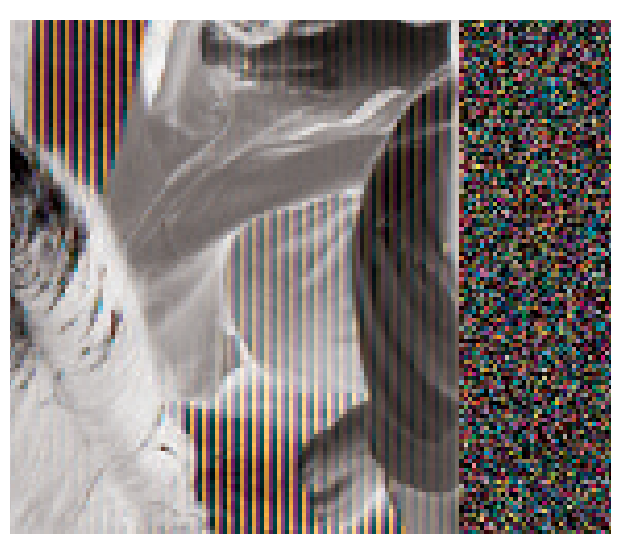

Jovens do CJ União em atividade de colagem de painel de lambe-lambes com seus retratos

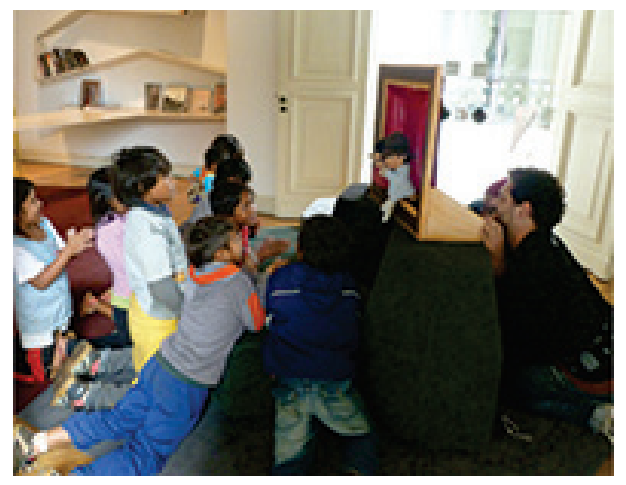

Crianças da aldeia Tekoa Pyau em visita à Pinacoteca 
onde a gravura em madeira tem papel de destaque na cultura popular. Os processos e resultados obtidos neste projeto já geraram exposições, tanto na Pinacoteca quanto nas casas de convivência, além de mostras temporárias em diferentes instituições culturais do estado de São Paulo. A partir desta experiência também foram desenvolvidas uma publicação de caráter documental e reflexivo sobre o papel socioinclusivo dos museus, além de álbuns com xilogravuras originais encadernadas. A mais recente publicação desenvolvida a partir dessa ação, chamada Plural, foi dedicada aos textos de caráter poético produzidos pelos participantes ao longo do processo.

No ano de 2013 iniciamos outra ação extramuros de características distintas, chamada Comunidade e Museu, inspirada na ação realizada no Museu de Antioquia, de Medellín, Colômbia e que acompanhamos em nossa passagem para uma visita técnica por este museu em 20I2. Para esse projeto, selecionamos junto aos parceiros dois grupos comunitários bastante distintos entre si a fim de desenvolver uma ação que busca promover o reconhecimento dos referenciais patrimoniais materiais e imateriais dos grupos, bem como elaborar estratégias para sua valorização e dinamização.

Dessa forma, desenvolvemos ao longo do ano de 2013 encontros semanais com um grupo de adolescentes da ONG Centro para Juventude União Cidade Líder (CJ União), localizada em bairro periférico da Zona Leste da cidade, nos quais por meio de diálogos propositivos e mídias de interesse desse público, como a fotografia digital, realizamos um levantamento dos valores que são atribuídos pelos participantes aos seus patrimônios pessoais e coletivos, resgatando com eles aquilo que os articula como grupo. $O$ resultado desta investigação foi documentado por meio de um jornal produzido por eles e de um painel de lambe-lambes com fotos de seus retratos no espaço da ONG.

De forma semelhante, realizamos encontros com a comunidade indígena Guarani da Aldeia Tekoa Pyau, localizada no Pico do Jaraguá, na Zona Oeste da cidade. Ali as questões identitárias se fazem sentir de maneiras distintas, posto que para resguardar-se dos sucessivos processos de conflito étnico, alguns membros desta comunidade em determinados momentos mostraram-se resistentes ao trabalho com o museu. Entretanto, uma vez percebido o respeito para com aquela cultura e seus sistemas únicos, o trabalho se desenvolveu focando dois grupos distintos da comunidade: um grupo de artesãos, composto majoritariamente por mulheres, e um grupo de crianças da aldeia. Com as crianças, o fascínio pelo desenho na representação de seu cotidiano permitiu o diálogo sobre sua cultura e com os artesãos, o trabalho de resgatar alguns pratos da culinária tradicional Guarani, deu chance de tratar a identidade e patrimônio desse povo. Estes encontros e diálogos resultaram na publicação de um pequeno livro de receitas tradicionais Guarani, com textos bilíngues (em português e Guarani), ilustrado com os desenhos dessas atividades feitos pelas crianças da comunidade. Também foram colados painéis de lambe-lambes com fotos das crianças em alguns espaços e casas da aldeia.

Com a ação Comunidade e Museu nos demos conta que o processo de educação com foco na identidade patrimonial local deve ter caráter continuado, pois percebemos que um ano de atividade é apenas o princípio, e que os diálogos construídos demonstram uma potencialidade mais ampla, sendo sempre uma via de mão dupla; nos acrescentando, como educadores, a possibilidade de repensar não apenas nossas práticas, mas promover constantemente a reflexão acerca de nossa função institucional. 
Neste sentido, em 20I4, esta ação continua em desenvolvimento, abarcando a mesma aldeia Guarani e atuando com outro grupo de adolescentes do Centro da Criança e Adolescente - CCA ABCD Nossa Casa, na região do bairro do Bom Retiro.

Nas perspectivas apresentadas acima fica claro que cremos que o museu, mais do que seus edifícios e objetos, permite processos de educação que ultrapassam seus limites físicos e podem expandir-se a outros locais e culturas promovendo processos de diálogo e articulando conhecimentos múltiplos.

No momento contemporâneo determinado pelo enfraquecimento das raízes culturais e identitárias em função dos processos de globalização e comunicação em rede, acreditamos que os processos educativos dos museus possam contribuir como possibilidade de autoconhecimento pessoal e coletivo, de valorização e fortalecimento de culturas locais e de reconhecimento do patrimônio como algo ligado ao cotidiano das pessoas, não apenas pertencente aos cânones institucionais do museu.

Da mesma forma entendemos que a função educativa cabe ao museu como um todo e não apenas a um determinado departamento, sendo que o ideal seria pensarmos em um museu, por natureza, educativo. Não apenas manter uma área de educação para difundir um conhecimento estático plasmado em seus objetos, ou em conhecimentos construídos à revelia de qualquer relação com as comunidades imediatas e ou sociedades nas quais se inserem.

Propomos que os museus sejam espaços de fórum, de conversação, de prazer aos quais se queira ir. Que estejam abertos à significação ampla de todos. Que sejam para todos e para cada um.

Que sejam o espaço da igualdade, e que o exercício da estética (no caso da arte) fosse também o exercício da ética, que o encontro com o objeto seja o propulsor da potencialidade de aceitação de múltiplos pontos de vista.

Que ao fruir os objetos do museu as sociedades possam repensar-se a si mesmas e ao mundo como um todo. Se assim fosse, não teríamos a educação no museu, mas um museu educador, no qual a educação seria feita como se faz na vida: em contato com as coisas reais, que nos possam inquietar e fazer duvidar do que vemos para que aprendamos, vividamente, com a mente, o espírito e o corpo, como fazemos na vida.

Acreditamos que a educação feita pelo museu, neste museu educador, seria, então, uma educação para e na vida, e que essa educação nos pudesse levar até o máximo de nossas potencialidades individuais e coletivas na construção de consciência social critica. É nesta instituição que além de nosso papel estético e ético, poderíamos assumir plenamente nosso papel político, como propõe a museóloga Waldisa Rússio:

(...) a preservação do patrimônio cultural é um ato e um fato político, e temos de assumi-lo como tal, mesmo nas nossas áreas específicas de atuação profissional. No caso do museólogo, trabalhador social, significa não recusar a dimensão e o risco político de seu trabalho. (Guarnieri, 2010: pg. 209).

A expressão "trabalhador social" apontada pela autora, na qual aqui incluímos museólogos, educadores e demais profissionais do museu, tem o sentido não apenas de quem exerce a função social do trabalho, mas de quem trabalha consciente com a dimensão social, colaborando com a mudança. 


\section{Referências}

ANDERSON, David. Creativity, learning and cultural rights. In: SANDELL, Richard \& NIGHTINGALE, Eithne (eds.) Museums, equality and social justice. London \& New York: Routledge, 2012.

CHIOVATTO, Milene;AIDAR, Gabriela; SOARES, Luis Roberto e AMARO, Daniele Rodrigues. Repensando a acessibilidade em museus: a experiência do Núcleo de Ação Educativa da Pinacoteca do Estado de São Paulo. Diálogos entre Arte e Público - Acessibilidade Cultural: o que é acessível e para quem? Recife: Fundação de Cultura Cidade do Recife, v. 3, 2010.

DE HAAN, Arjan \& MAXWELL, Simon. Poverty and social exclusion in North and South. International Development Studies Bulletin, vol. 29, n. I, 1998.

FREIRE, Paulo. Pedagogia do oprimido. Rio de Janeiro: Paz e Terra, 2005.

GUARNIERI,Waldisa Rússio Camargo. Conceito de cultura e sua inter-relação com o patrimônio cultural e a preservação. In: BRUNO, Maria Cristina Oliveira (org.). Waldisa Rússio Camargo Guarnieri: textos e contextos de uma trajetória profissional. São Paulo: Pinacoteca do Estado: Secretaria de Estado da Cultura: Comitê Brasileiro do Conselho Internacional de Museus, 2010.

KERSHAW, Anne. The promise and challenge of community involvement in museums. ICOM News 66, vol. 66, n. I, março de 2013.

MINISTÉRIO DA CULTURA. Conselho Nacional de Política Cultural. Secretaria de Articulação Institucional. Coordenação Geral de Relações Federativas e Sociedade. Guia de Orientações para os Municípios. Sistema Nacional de Cultura Perguntas e Respostas. Brasília: maio de 20II.

O'NEILL, Mark. The good enough visitor. In: SANDELL, Richard (ed.) Museums, society, inequality. London \& New York: Routledge, 2002.

Pinacoteca do Estado de São Paulo. Pesquisa de perfil de público visitante da Pinacoteca - Você e o museu (2002).

Política Nacional de Assistência Social - versão oficial. Revista Serviço Social \& Sociedade, n. 80, encarte, nov. 2004. 
148

옴

ซั

공

븐

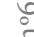

当

띨

究 